\title{
The 2017 Hurricane Public Health Responses: Case Studies Illustrating the Role of Centers for Disease Control and Prevention's Public Health Emergency Preparedness Program - Erratum
}

DeAndrea Martinez, MPH; Kelcie A. Landon, MPH; Wesley McDermott, MSPH; Joseph Roth Jr, DrPH CAPT, USPHS; Amy Helene Schnall, MPH; Todd P. Talbert, MA; Hugh M. Mainzer, MS, DVM, Dipl. ACVPM

doi: 10.1017/dmp.2020.75, Published by Cambridge University Press, 26 May 2020.

Key Words: disaster planning, emergency preparedness, natural disasters, public health, public health surveillance, erratum

T the original publication of this article ${ }^{1}$, the title was incorrect, and the key words were left out. The article has since been corrected.

The publisher apologizes for the error.

\section{Reference}

1. Martinez D, Landon KA, McDermott W et al. The 2017 hurricane public health responses: case studies illustrating the role of Centers for Disease Control and Prevention's public health emergency preparedness program. Disaster Med Public Health Preparedness. 2020. doi: $10.1017 / \mathrm{dmp} .2020 .75$. 